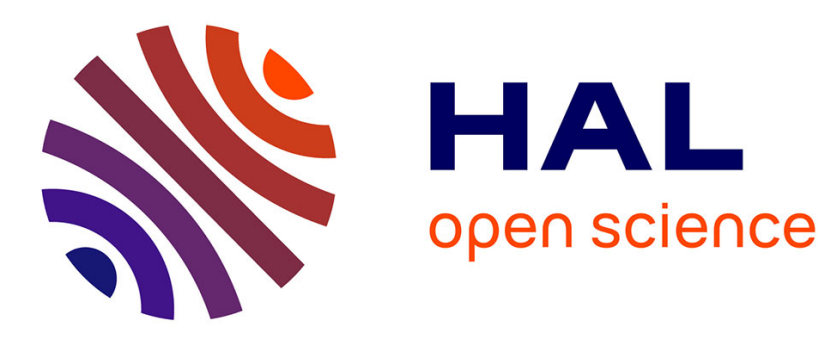

\title{
Growth kinetics of Si on fullsheet, patterned and silicon-on-insulator substrates
}

J.M. Hartmann, A. Abbadie, M. Vinet, L. Clavelier, P. Holliger, D. Lafond, M. N Séméria, P. Gentile

\section{- To cite this version:}

J.M. Hartmann, A. Abbadie, M. Vinet, L. Clavelier, P. Holliger, et al.. Growth kinetics of Si on fullsheet, patterned and silicon-on-insulator substrates. Journal of Crystal Growth, 2003, 257, pp.1930. 10.1016/s0022-0248(03)01380-0 . cea-01989757

\section{HAL Id: cea-01989757 https://hal-cea.archives-ouvertes.fr/cea-01989757}

Submitted on 22 Jan 2019

HAL is a multi-disciplinary open access archive for the deposit and dissemination of scientific research documents, whether they are published or not. The documents may come from teaching and research institutions in France or abroad, or from public or private research centers.
L'archive ouverte pluridisciplinaire HAL, est destinée au dépôt et à la diffusion de documents scientifiques de niveau recherche, publiés ou non, émanant des établissements d'enseignement et de recherche français ou étrangers, des laboratoires publics ou privés. 


\title{
Growth kinetics of Si on fullsheet, patterned and silicon-on-insulator substrates
}

\author{
J.M. Hartmann ${ }^{\mathrm{a}, *}$, A. Abbadie ${ }^{\mathrm{a}}$, M. Vinet ${ }^{\mathrm{a}}$, L. Clavelier ${ }^{\mathrm{a}}$, P. Holliger ${ }^{\mathrm{a}}$, D. Lafond $^{\mathrm{a}}$, \\ M.N. Séméria ${ }^{a}$, P. Gentile \\ ${ }^{\text {a } C E A-D R T, ~ L E T I / D T S, ~ C E A / G R E-17, ~ A v e n u e ~ d e s ~ M a r t y r s, ~ F-38054 ~ G r e n o b l e ~ C e d e x ~ 9, ~ F r a n c e ~}$ \\ ${ }^{\mathrm{b}}$ DRFMC, CEA/GRE-17, Avenue des Martyrs, F-38054 Grenoble Cedex 9, France
}

Received 10 April 2003; accepted 13 May 2003

Communicated by R. Kern

\begin{abstract}
Using a reduced pressure-chemical vapor deposition cluster tool, we have studied the epitaxial growth of Si using either a silane or a dichlorosilane + hydrochloric acid chemistry on fullsheet, patterned and silicon-on-insulator (SOI) substrates. We have first of all developed a ("HF-last" advanced wet cleaning + low thermal budget $\left(775^{\circ} \mathrm{C}, 2 \mathrm{~min}\right)$ in situ $\mathrm{H}_{2}$ bake) combination that yields atomically smooth, contamination free Si starting surfaces for both fullsheet and patterned wafers. We have then modeled the low temperature Si growth rate (silane or dichlorosilane + hydrochloric acid chemistry) on fullsheet wafers. A similar growth rate activation energy is found for both chemistries, i.e. $E_{\mathrm{GR}} \sim 50 \mathrm{kcal} \mathrm{mol}^{-1}$. The growth rate dependency on the Si precursor flow is vastly different, however. Fitting this dependency with a simple power law, a value of 0.36 is indeed associated to dichlorosilane, versus 0.92 for silane. The $\mathrm{HCl}$ etching rate is characterized by an activation energy $E_{\mathrm{ER}} \sim 34 \mathrm{kcal} \mathrm{mol}^{-1}$, with a 0.52 power law dependency on the $\mathrm{HCl}$ flow. On patterned wafers, we have demonstrated that a deposited Si thickness limit $(20 \mathrm{~nm})$ exists at $775^{\circ} \mathrm{C}$ for high $F(\mathrm{HCl}) / F\left(\mathrm{SiH}_{2} \mathrm{Cl}_{2}\right)$ mass flow ratios. This limit disappears when (i) $F(\mathrm{HCl}) / F\left(\mathrm{SiH}_{2} \mathrm{Cl}_{2}\right)$ is reduced (ii) the growth temperature is increased to $800^{\circ} \mathrm{C}$. Finally, we have highlighted the specifics of the growth on SOI wafers. A significant growth rate reduction (compared to bulk $\mathrm{Si}$ ) has been evidenced on ultra-thin $\mathrm{Si}$ over-layer SOI wafers. It gets less and less pronounced as the buried oxide layer gets thinner and/or the Si over-layer thickness increases.
\end{abstract}

(C) 2003 Elsevier B.V. All rights reserved.

PACS: 81.15.Gh; 81.15.Aa; 68.55.-a

Keywords: A1. Fullsheet; A1. Patterned and SOI wafers; A1. Si growth kinetics; A1. Surface preparation; A3. Reduced pressurechemical vapor deposition

\section{Introduction}

In the last few years, there has been significant interest in $\mathrm{SiGe}$ epitaxial growth on silicon

\footnotetext{
*Corresponding author.

E-mail address: jmhartmann@cea.fr (J.M. Hartmann).
}

substrates, because $\mathrm{Si} / \mathrm{SiGe}$ heterostructures allow band gap engineering to be used in conjunction with silicon technology [1] in field effect transistors [2,3], photodetectors [4], etc.

We propose in this paper a study of the growth kinetics of $\mathrm{Si}$ in reduced pressure-chemical vapor deposition (RP-CVD) on fullsheet, patterned and 
silicon-on-insulator (SOI) substrates. Two precursor chemistries were used: either silane [5] or dichlorosilane + hydrochloric acid [6]. It is possible using the latest chemistry (i.e. the chlorinated one) to selectively grow high quality $\mathrm{Si}$ [7-10] layers inside the $\mathrm{Si}$ windows of $\mathrm{SiO}_{2}$ or $\mathrm{Si}_{3} \mathrm{~N}_{4}$-masked $\mathrm{Si}$ wafers, making it useful for the formation of Si raised sources and drains [11,12]. The knowledge of the specifics of the growth of $\mathrm{Si}$ on SOI wafers will be put to good use for the deposition of tensile-strained $\mathrm{Si}$ layers on top of nearly fully relaxed $\mathrm{SiGe}$-on-insulator (SGOI) substrates [13-15].

As far as the experimental results are concerned, the article is organized as follows. We will first focus on the surface preparation (ex situ wet cleaning followed by an in situ low temperature $\mathrm{H}_{2}$ bake) of fullsheet and patterned wafers prior to epitaxy. We will then present a semi-empirical modeling of the low temperature $\mathrm{Si}$ growth rate on fullsheet wafers for the hydrogenated and the chlorinated chemistries. We will highlight the specifics of the selective epitaxial growth of $\mathrm{Si}$ with the dichlorosilane + hydrochloric acid chemistry on patterned wafers. We will notably focus on the role of the growth temperature and of the $F(\mathrm{HCl}) / F\left(\mathrm{SiH}_{2} \mathrm{Cl}_{2}\right)$ mass flow ratio on the $\mathrm{Si}$ thickness that can be deposited inside the $\mathrm{Si}$ windows. Finally, we will quantify on SOI wafers the impact of both the buried oxide and Si overlayer thickness on the Si growth kinetics.

\section{Experimental details}

We have grown the Si layers with an Epi Centura RP-CVD industrial cluster tool (manufactured by Applied Materials). The $\mathrm{Si}\left(\begin{array}{ll}0 & 01)\end{array}\right.$ substrates used are nominal $\left( \pm 0.25^{\circ}\right)$ and slightly p-type doped (resistance in the $7-10 \Omega \mathrm{cm}$ range). During the growth, the wafer lies horizontally on top of a circular SiC-coated susceptor plate that rotates to improve thickness uniformity. The substrate is heated by two banks of 20 tungstenhalogen lamps (maximum power: $2 \mathrm{~kW}$ each) located above and below the susceptor assembly. It is therefore heated by thermal radiation coming from the upper lamps bank, as well as by thermal conduction from the susceptor underneath. Temperature monitoring and control is ensured through the lower pyrometer, i.e. the one which is looking at the backside of the susceptor plate on which the wafer lies. The reading is therefore independent of the nature of the substrate (fullsheet, patterned or SOI). It is only the heat transfer by radiation from the upper lamp-bank that can be affected by changes in wafer surface emissivity during Si deposition [16]. In our study, the growth pressure was always 20 Torr. The flow of $\mathrm{H}_{2}$ carrier gas was set at a fixed value of a few tens of standard liters per minute (slms), which was not altered throughout all the experiments. Pure dichlorosilane $\left(\mathrm{SiH}_{2} \mathrm{Cl}_{2}\right.$ or DCS) and pure silane $\left(\mathrm{SiH}_{4}\right)$ were used as the sources of $\mathrm{Si}$.

A Akrion Gama One automated wet bench was used for the ex situ cleaning of our substrates. The secondary ion mass spectrometry (SIMS) measurements were carried out on a Cameca IMS $5 f$ spectrometer. $\mathrm{Cs}^{+}$primary ions were used for carbon, oxygen, fluorine and germanium depth profiling, with an impact energy of $2 \mathrm{keV}$. The atomic masses monitored were those of $\mathrm{Cs}_{2} \mathrm{C}^{+}$ $(133 \times 2+12=278 \mathrm{amu}), \quad \mathrm{Cs}_{2} \mathrm{O}^{+} \quad(133 \times 2+16=$ $282 \mathrm{amu}), \quad \mathrm{Cs}_{2} \mathrm{~F}^{+} \quad(133 \times 2+19=285 \mathrm{amu})$ and $\mathrm{Cs}_{2} \mathrm{Si}^{+} \quad(133 \times 2+28=294 \mathrm{amu})$ [17]. Cross-sectional transmission electron microscopy imaging was performed on an Akashi EM-002B (fitted with an ultra-high resolution pole piece) that was operated at $200 \mathrm{kV}$. A Digital Instrument 3100 SPM platform fitted with a camera was used for the tapping-mode atomic force microscopy (AFM) imaging of the surface morphology. Scanning tunneling microscopy (STM) was carried out in ultra-high vacuum using an Omicron apparatus. Finally, spectroscopic ellipsometry (SE) measurements were carried on a SE 1280 Ellipsometer from KLA-Tencor.

The Si thickness deposited was determined in three different ways depending on the nature of the substrate:

- On bulk, fullsheet wafers, the $200 \mathrm{~mm}$ wafer was scaled on a micro-balance prior and just after the epitaxy step. The average thickness deposited on a $200 \mathrm{~mm}$ wafer is then given by: $t(\mathrm{~cm})=\Delta m /\left(\pi R^{2} \rho\right)(\Delta m$ is the weight difference 
(g), $R(=10 \mathrm{~cm})$ is the radius of the wafer and $\rho=2.328 \mathrm{~g} / \mathrm{cm}^{3}$ is the Si density).

- On bulk, patterned wafers, the Si thickness deposited was determined through a step height difference measurement in AFM at the boundary between a $\mathrm{Si}$ window and the dielectric masking material [18].

- On SOI wafers, the Si thickness deposited is determined through a differential measurement in SE of the Si over-layer thickness before and after the epitaxy step.

\section{Surface preparation}

It is of the utmost importance when growing layers epitaxially on fullsheet, patterned or SOI wafers to start from a mono-crystalline Si surface free of any particles or contaminants.

We have used a variant, which we have named "EpiClean" [18], of the so-called "Low Consumption Front End of Line" (LC-FEOL) wet cleaning [19] to prepare the surface of our samples. This cleaning, whose last three steps are a $2.5 \mathrm{~min}$ dip into a HF:HCl:De-ionised water (DIW) bath $\left(0.2 / 1 / 100\right.$ at $\left.23^{\circ} \mathrm{C}\right)$ followed by a DIW rinse and an Iso-Propylic Alcohol vapor drying [18], generate "HF-last", Si(0 01$)$ passivated surfaces [20], i.e. surfaces with dangling bonds being mostly occupied by $\mathrm{H}$ or $\mathrm{F}$ atoms that are stable for a few tens of minutes in ambient conditions, enabling sample transfer and loading. An $\mathrm{H}_{2}$-bake, typically between $800^{\circ} \mathrm{C}$ and $900^{\circ} \mathrm{C}$ for a few tens of seconds up to a few minutes $[11,21-26]$, will lead to the removal of any $\mathrm{C}, \mathrm{O}$ or $\mathrm{F}$ residual atoms and to the formation of smooth [24,27] $(2 \times 1): \mathrm{H}$ reconstructed surfaces that are much more stable in the air [28] (up to $40 \mathrm{~h}$ [29]).

Several groups have tried to minimize the thermal budget necessary for the $\mathrm{H}_{2}$ bake $[21,25,26,30]$. What has been found on fullsheet wafers is that an optimized wet clean [last step: 1:1000 $\mathrm{HF}(49 \%)$ :deionized water] followed by an $\mathrm{H}_{2}$ bake at $800^{\circ} \mathrm{C}$ for $2 \mathrm{~min}$ is sufficient at 10 Torrs to produce oxygen and carbon-free $\mathrm{Si}$ surfaces [26]. We have tried to extend those findings for patterned wafers.
We have therefore cleaned fullsheet and patterned wafers with the above-mentioned "EpiClean" wet cleaning, loaded those samples inside the load-locks of our cluster tool, then purged those load-locks with $\mathrm{N}_{2}$. The samples have then been transferred over to the RP-CVD chamber, where they have been submitted at 20 Torrs to an 2 min $\mathrm{H}_{2}$ bake at either $775^{\circ} \mathrm{C}$ or $750^{\circ} \mathrm{C}$, followed by the deposition of $60 \mathrm{~nm}$ of $\mathrm{Si}$ at $750^{\circ} \mathrm{C}$ using $\mathrm{SiH}_{2} \mathrm{Cl}_{2}$. We have profiled in SIMS (see Figs. 1 and 2) the $\mathrm{C}, \mathrm{O}$ and $\mathrm{F}$ atoms in those samples. No peak has been observed for those elements at the Si epilayer/substrate interface at $775^{\circ} \mathrm{C}$, this whatever the nature of the substrates (fullsheet or patterned). Meanwhile, $750^{\circ} \mathrm{C}$ seems to be too small a temperature (at least for $2 \mathrm{~min}_{2}$ bakes) to get rid of those impurities, as attested by the peaks in SIMS at the interface between the Si epilayer and the substrate on a fullsheet wafer (see Fig. 1). For the sake of completeness, it should nevertheless be mentioned that no such peaks were observed for this bake temperature of $750^{\circ} \mathrm{C}$ on the corresponding patterned wafer. The temperature boundary between cleaned and contaminated wafers must therefore be slightly above $750^{\circ} \mathrm{C}$.

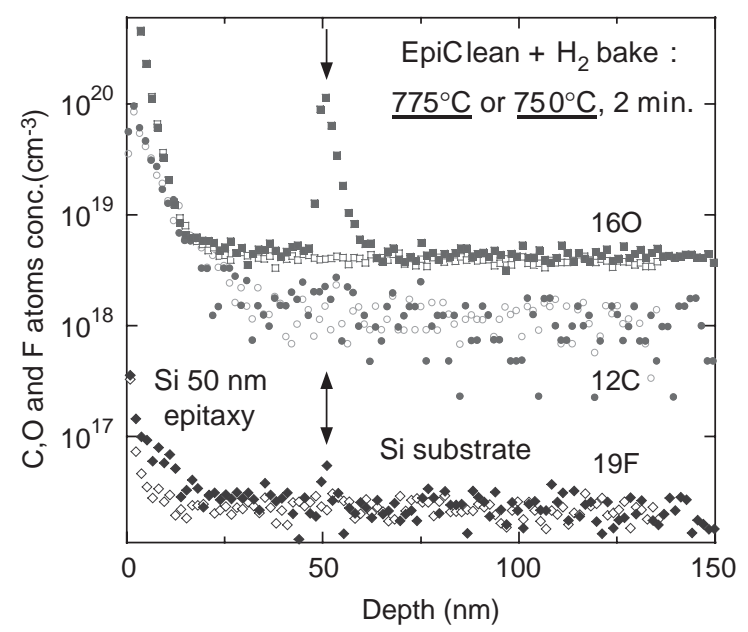

Fig. 1. SIMS depth profile of the $\mathrm{O}, \mathrm{C}$ and $\mathrm{F}$ atoms in the $\mathrm{Si}$ epilayers grown on fullsheet wafers after a ex situ "EpiClean" wet cleaning followed by an in situ $\mathrm{H}_{2}$ bake either at either $775^{\circ} \mathrm{C}$ (open symbols) or at $750^{\circ} \mathrm{C}$ (full symbols) for $2 \mathrm{~min}$ $(P=20$ Torrs $)$. 


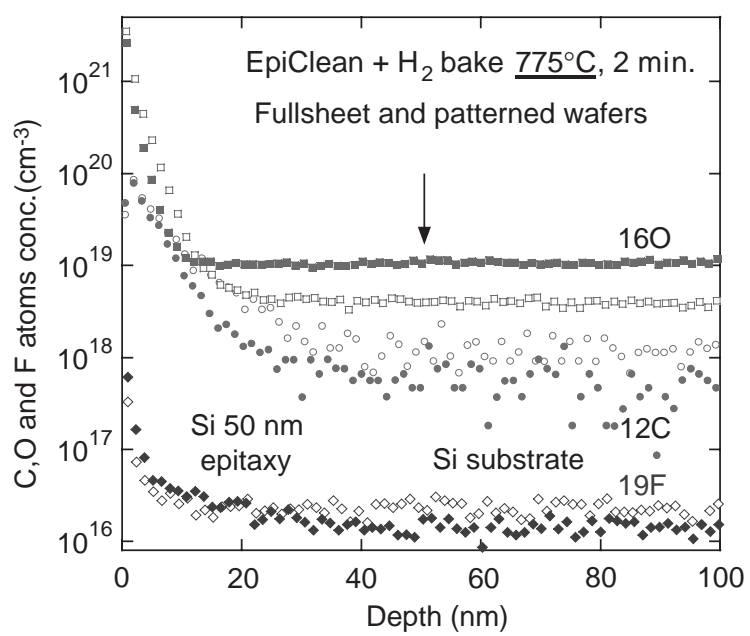

Fig. 2. SIMS depth profile of the $\mathrm{O}, \mathrm{C}$ and $\mathrm{F}$ atoms in the $\mathrm{Si}$ epilayers grown on either a fullsheet wafer (open symbols) or a patterned wafer (full symbols) after a \{ex situ "EpiClean" wet cleaning $+\mathrm{H}_{2}$ bake at $775^{\circ} \mathrm{C}, 20$ Torrs for $2 \mathrm{~min}$ \} surface preparation. SIMS profiling was carried out inside a large $\mathrm{Si}$ window for the patterned wafer.

This conclusion is supported by the finding of Brabant et al. [30], who have found that neither a $10 \mathrm{~min}$ nor a $20 \mathrm{~min}$ bake under $\mathrm{H}_{2}$ at $750^{\circ} \mathrm{C}$ does enable to completely get rid of the interfacial oxyde. They have indeed obtained in SIMS a small $O$ peak at the interface (maximum: $\sim 10^{19}\left(\sim 10^{18}\right)$ $\mathrm{cm}^{-3}$, integrated dose: $2.5 \times 10^{12}\left(2.34 \times 10^{11}\right)$ $\mathrm{cm}^{-2}$ for a $10 \mathrm{~min}(20 \mathrm{~min}) \mathrm{H}_{2}$ bake at $\left.750^{\circ} \mathrm{C}\right)$. No C peak was obtained in both cases, however.

A STM image of the surface of a fullsheet wafer that has been cleaned ex situ using the "EpiClean" process followed by an in situ $\mathrm{H}_{2}$ bake at $775^{\circ} \mathrm{C}$ for $2 \mathrm{~min}$ is plotted in Fig. 3. The surface is atomically smooth, with mono-atomic steps either straight $\left(S_{\mathrm{A}}\right.$-type $)$ or meandering $\left(S_{\mathrm{B}}\right.$-type) $[31,32]$ delimiting either $(1 \times 2)$ or $(2 \times 1)$-reconstructed, a few tens of $\mathrm{nm}$ wide, terraces. The root mean square roughness of that surface is equal to $0.9 \AA$.

We can therefore conclude that an "EpiClean" ex situ wet clean followed by an in situ $\mathrm{H}_{2}$ bake at $775^{\circ} \mathrm{C}, 20$ Torrs for $2 \mathrm{~min}$ is an efficient, low-thermal budget combination to obtain atomically smooth surfaces free of any residual contamination.

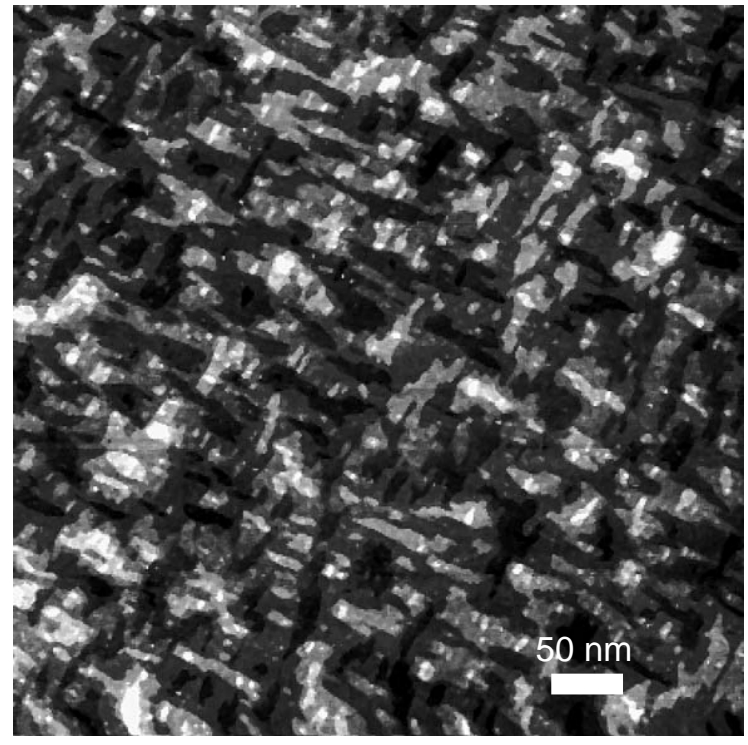

Fig. 3. STM image $(500 \mathrm{~nm} \times 500 \mathrm{~nm})$ of the surface of a blanket $\operatorname{Si}\left(\begin{array}{lll}0 & 0 & 1\end{array}\right)$ substrate that has been cleaned ex situ with an "EpiClean" recipe followed by an in situ $\mathrm{H}_{2}$ bake at $775^{\circ} \mathrm{C}$ for $2 \mathrm{~min}$. Sample bias voltage: $+2.8 \mathrm{~V}$, tunneling current: $80 \mathrm{pA}$.

\section{Si growth kinetics on fullsheet wafers}

\subsection{The dichlorosilane+hydrochloric acid chemistry}

Simply speaking, the growth of $\mathrm{Si}$ using a $\mathrm{SiH}_{2} \mathrm{Cl}_{2}+\mathrm{HCl}$ chemistry is expected to take place according to the following three equations $[9,33]$ :

- $\mathrm{SiH}_{2} \mathrm{Cl}_{2}$ thermally dissociates in the gas phase into $\mathrm{SiCl}_{2}$ and $\mathrm{H}_{2}$ :

$$
\mathrm{SiH}_{2} \mathrm{Cl}_{2}(\mathrm{~g}) \rightleftharpoons \mathrm{SiCl}_{2}(\mathrm{~g})+\mathrm{H}_{2}(\mathrm{~g})
$$

- Deposition of Si occurs through the reduction of the adsorbed $\mathrm{SiCl}_{2}$ on a free surface site by hydrogen:

$$
\mathrm{SiCl}_{2}^{*}+\mathrm{H}_{2}(\mathrm{~g}) \rightarrow \mathrm{Si}(\mathrm{s})+2 \mathrm{HCl}(\mathrm{g})
$$

- If enough additional external $\mathrm{HCl}$ is added to the system at a given pressure and temperature, silicon etching occurs through:

$$
\mathrm{Si}^{*}+2 \mathrm{HCl}(\mathrm{g}) \rightarrow \mathrm{SiCl}_{2}^{*}+\mathrm{H}_{2}(\mathrm{~g})
$$


If the quantity of $\mathrm{HCl}$ added to the system is optimized, silicon atoms are removed on a patterned wafer from the dielectric mask before they form stable polysilicon nuclei. The SEG of Si can therefore be visualized as a sum of the growth effect, which is dependent of the abundance of adsorbed $\mathrm{SiCl}_{2}$, and the etching effect, which is dependent upon the partial pressure of $\mathrm{HCl}$.

The low-temperature $\left(750^{\circ} \mathrm{C} \leqslant T \leqslant 850^{\circ} \mathrm{C}\right) \mathrm{Si}$ growth rate modelling we have adopted here is based on the work of Kongetira et al. [33]. They have fitted their $\mathrm{Si}$ growth rate dependence on the $\mathrm{SiH}_{2} \mathrm{Cl}_{2}$ and $\mathrm{HCl}$ partial pressures, on the growth temperature and pressure with the following semiempirical expression:

$$
\begin{aligned}
\mathrm{GR} & (\mu \mathrm{m} / \mathrm{min}) \\
= & \frac{k_{\mathrm{GR}}(\mathrm{DCS}) \mathrm{e}^{-E_{\mathrm{GR}}(\mathrm{DCS}) / k_{\mathrm{B}} T}\left(P_{\mathrm{DCS}}\right)^{z}\left(P_{\mathrm{H}_{2}}\right)^{x}}{\Delta} \\
& -\frac{k_{\mathrm{ET}} \mathrm{e}^{-E_{\mathrm{ET}} / k_{\mathrm{B}} T}\left(P_{\mathrm{HCl}}\right)^{y}}{\Delta}
\end{aligned}
$$

where $E_{\mathrm{GR}}(\mathrm{DCS})$ and $E_{\mathrm{ET}}$ are activation energies for the growth and for the etching of $\mathrm{Si}$, respectively. $k_{\mathrm{GR}}$ (DCS) and $k_{\mathrm{ET}}$ are rate constants for the growth and for the etching of $\mathrm{Si}$, respectively. $\Delta$ is a pressure-related factor. Having been fixed arbitrarily by Kongetira et al. to 1 for a growth pressure of 40 Torrs, it has been found to vary linearly with the growth pressure (in Torrs) in the following manner: $\Delta=0.06 P-1.4 . P_{\mathrm{DCS}}, P_{\mathrm{H}_{2}}$ and $P_{\mathrm{HCl}}$ are the incoming flows' partial pressures (in Torrs). $k_{\mathrm{B}}$ and $T$ are the Boltzmann constant and the absolute growth temperatures, respectively. $x$ has been fixed to 1.0 in Kongetira et al.'s work.

We have consequently made the following assumptions for the modeling of our experimental data: $\Delta$ is arbitrarily fixed to 1.0 at 20 Torrs (instead of 40 Torrs), $x$ is equal to 1.0. Let us now focus on the determination of $E_{\mathrm{GR}}, k_{\mathrm{GR}}$ and $z$. Without any incoming flow of $\mathrm{HCl}$, the $\mathrm{Si}$ growth rate is given by:

$$
\begin{aligned}
& \mathrm{GR}_{\text {without added } \mathrm{HCl}}(\mathrm{nm} / \mathrm{min}) \\
& \quad=k_{\mathrm{GR}}(\mathrm{DCS}) \mathrm{e}^{-E_{\mathrm{GR}}(\mathrm{DCS}) / k_{\mathrm{B}} T}\left(P_{\mathrm{DCS}}\right)^{z}\left(P_{\mathrm{H}_{2}}\right) .
\end{aligned}
$$

Using an Arrhenius plot of the Si growth rate without $\mathrm{HCl}$ as a function of the reverse absolute temperature (see Fig. 4), it is quite easy to determine $E_{\mathrm{GR}}$ (DCS). $E_{\mathrm{GR}}$ (DCS) has been found

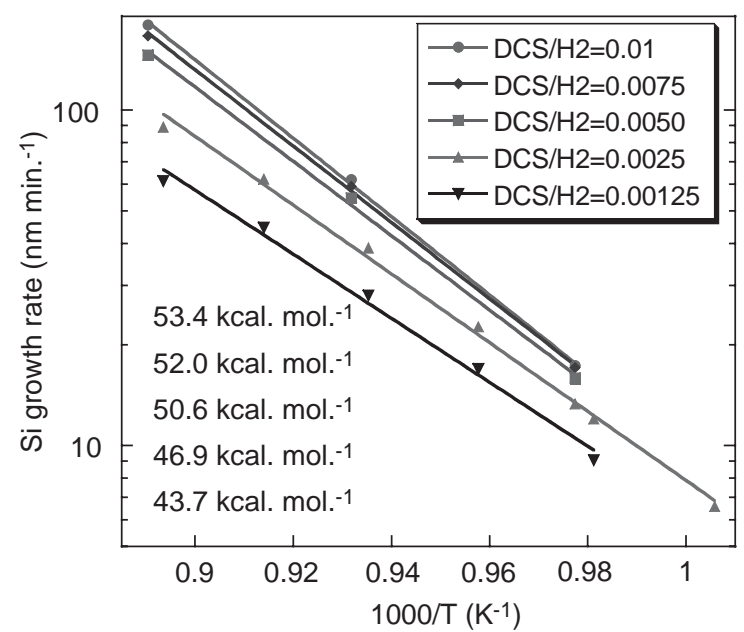

Fig. 4. Arrhenius plot of the $\mathrm{Si}$ growth rate as a function of the reverse absolute temperature for several $F\left(\mathrm{SiH}_{2} \mathrm{Cl}_{2}\right) / F\left(\mathrm{H}_{2}\right)$ mass flow ratios. The associated activation energies $E_{\mathrm{GR}}$ (DCS) are reported in the figure.

to increase monotonously from 43.7 up to $53.4 \mathrm{kcal} \mathrm{mol}^{-1}$ with the $\mathrm{SiH}_{2} \mathrm{Cl}_{2}$ partial pressure, which is to the best of our knowledge the first time that such a behavior is reported. A mean value of $49.3 \mathrm{kcal} \mathrm{mol}^{-1}$ is associated to $E_{\mathrm{GR}}$ (DCS), to be compared to the $52.2 \mathrm{kcal} \mathrm{mol}^{-1}$ value of Kongetira et al. [33]. This exponential dependence of the $\mathrm{Si}$ growth rate on the reverse absolute temperature is in fact related to the desorption of hydrogen from the silicon surface in order for silicon atoms to be incorporated. An activation energy of $47 \mathrm{kcal} \mathrm{mol}^{-1}$ has indeed been found for hydrogen desorption from a $\mathrm{Si}\left(\begin{array}{lll}1 & 0 & 0\end{array}\right)$ surface [34].

We have then plotted at $750^{\circ} \mathrm{C}, 800^{\circ} \mathrm{C}$ and $850^{\circ} \mathrm{C}$ the $\mathrm{Si}$ growth rate without $\mathrm{HCl}$ as a function of the DCS partial pressure in order to determine $k_{\mathrm{GR}}$ (DCS) and $z$ (see Fig. 5). Mean values of $6.4 \times 10^{10}$ and $z=0.36$ are associated to those two constants. Our $z$ value is half the one of Kongetira et al. (0.7).

We thus have three unknowns remaining, $E_{\mathrm{ET}}$, $k_{\mathrm{ET}}$ and $y$. The $\mathrm{Si}$ growth rate with some $\mathrm{HCl}$ added is given by:

$$
\begin{aligned}
\mathrm{GR}_{\text {with some } \mathrm{HCl} \text { added }}(\mathrm{nm} / \mathrm{min}) \\
=k_{\mathrm{GR}}(\mathrm{DCS}) \mathrm{e}^{-E_{\mathrm{GR}}(\mathrm{DCS}) / k_{\mathrm{B}} T}\left(P_{\mathrm{DCS}}\right)^{z}\left(P_{\mathrm{H}_{2}}\right) \\
\quad-k_{\mathrm{ET}} \mathrm{e}^{-E_{\mathrm{ET}} / k_{\mathrm{B}} T}\left(P_{\mathrm{HCl}}\right)^{y} .
\end{aligned}
$$




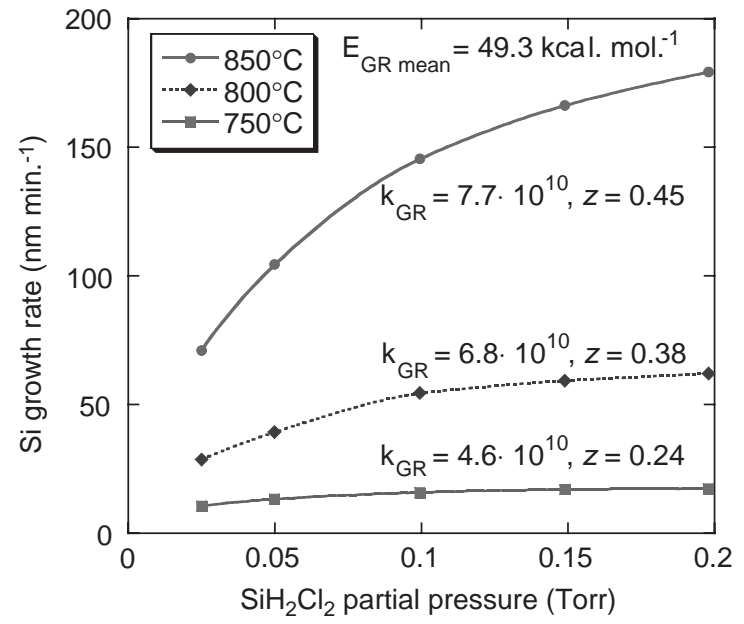

Fig. 5. Si growth rate at $750^{\circ} \mathrm{C}, 800^{\circ} \mathrm{C}$ and $850^{\circ} \mathrm{C}$ as a function of the dichlorosilane partial pressure. The associated $k_{\mathrm{GR}}$ (DCS) and $z$ values are given next to each curve.

The etching rate by $\mathrm{HCl}$ is thus given by (for a given value of the $\mathrm{SiH}_{2} \mathrm{Cl}_{2}$ flow):

$$
\begin{aligned}
& \mathrm{ER}(\mathrm{nm} / \mathrm{min})=k_{\mathrm{ET}} \mathrm{e}^{-E_{\mathrm{ET}} / k_{\mathrm{B}} T}\left(P_{\mathrm{HCl}}\right)^{y} \\
& \quad=\mathrm{GR}_{\text {without } \mathrm{HCl} \text { added }}-\mathrm{GR}_{\text {with some } \mathrm{HCl} \text { added }} .
\end{aligned}
$$

Proceeding in the same way as before (Arrhenius plot of the etching rate as a function of the reverse absolute temperature, see Fig. 6), values for $E_{\mathrm{ET}}$ can be obtained. A mean value of $34.3 \mathrm{kcal} \mathrm{mol}^{-1}$ is associated to this etching rate activation energy, to be compared to the $31.1 \mathrm{kcal} \mathrm{mol}^{-1}$ value of Kongetira et al.

We have then plotted at $750^{\circ} \mathrm{C}, 800^{\circ} \mathrm{C}$ and $850^{\circ} \mathrm{C}$ the $\mathrm{Si}$ etching rate as a function of the $\mathrm{HCl}$ partial pressure to determine $k_{\mathrm{ET}}$ and $y$ (see Fig. 7). Mean values of $1.4 \times 10^{9}$ and $y=0.52$ are associated to those two constants. Our $y$ value is much lower than the one of Kongetira et al. (1.2).

The $\mathrm{Si}$ growth rate (at 20 Torrs on blanket wafers) as a function of the $\mathrm{SiH}_{2} \mathrm{Cl}_{2}$ and $\mathrm{HCl}$ partial pressures (in Torr) and of the absolute temperature is thus given by:

$$
\begin{aligned}
\mathrm{GR}(\mathrm{nm} / \mathrm{min})= & 6.4 \times 10^{10} \mathrm{e}^{-49.3 \mathrm{kcal} \mathrm{mol}^{-1} / k_{\mathrm{B}} T} \\
& \times\left(P_{\mathrm{DCS}}\right)^{0.36}\left(P_{\mathrm{H}_{2}}\right)-1.4 \times 10^{9} \\
& \times \mathrm{e}^{-34.3 \mathrm{kcal} \mathrm{mol}^{-1} / k_{\mathrm{B}} T}\left(P_{\mathrm{HCl}}\right)^{0.52} .
\end{aligned}
$$

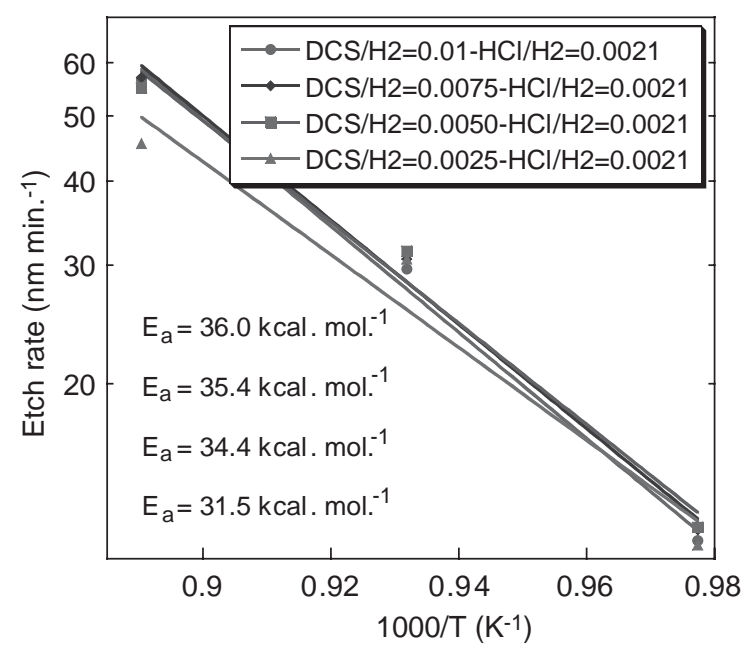

Fig. 6. Arrhenius plot of the $\mathrm{Si}$ etch rate by $\mathrm{HCl}$ as a function of the reverse absolute temperature for several $F\left(\mathrm{SiH}_{2} \mathrm{Cl}_{2}\right) / F\left(\mathrm{H}_{2}\right)$ mass flow ratios. The associated activation energies $E_{\mathrm{ER}}$ are reported in the figure.

This expression is valid in the low-temperature, $\mathrm{H}$-desorption limited regime (i.e. $T \leqslant 850^{\circ} \mathrm{C}$ ).

\subsection{The silane chemistry}

By analogy with the model adopted just above for the dichlorosilane + hydrochloric acid chemistry, we have decided to use for the low-temperature $\left(700^{\circ} \mathrm{C} \leqslant T \leqslant 800^{\circ} \mathrm{C}\right)$ modeling of the $\mathrm{Si}$ growth rate with a silane chemistry the following equation:

$$
\begin{aligned}
& \mathrm{GR}(\mathrm{nm} / \mathrm{min}) \\
& \quad=k_{\mathrm{GR}}\left(\mathrm{SiH}_{4}\right) \mathrm{e}^{-E_{\mathrm{GR}}\left(\mathrm{SiH}_{4}\right) / k_{\mathrm{B}} T}\left(P_{\left.\mathrm{SiH}_{4}\right)^{w}\left(P_{\mathrm{H}_{2}}\right)}\right.
\end{aligned}
$$

We have determined from an Arrhenius plot of the $\mathrm{Si}$ growth rate as a function of the reverse absolute temperature (as in Fig. 4) the growth activation energy $E_{\mathrm{GR}}\left(\mathrm{SiH}_{4}\right)$ for several silane mass flows $\left(F\left(\mathrm{SiH}_{4}\right) / F\left(\mathrm{H}_{2}\right)\right.$ in between 0.0025 and 0.01$)$. In opposition to dichlorosilane, the growth activation energy does not really depend upon the silane flow. A value of $50.0 \pm$ $0.8 \mathrm{kcal} \mathrm{mol}^{-1}$ is found for $E_{\mathrm{GR}}\left(\mathrm{SiH}_{4}\right)$, very close to the mean activation energy found for the dichlorosilane chemistry, i.e. $E_{\mathrm{GR}}(\mathrm{DCS})=$ $49.3 \mathrm{kcal} \mathrm{mol}^{-1}$. 


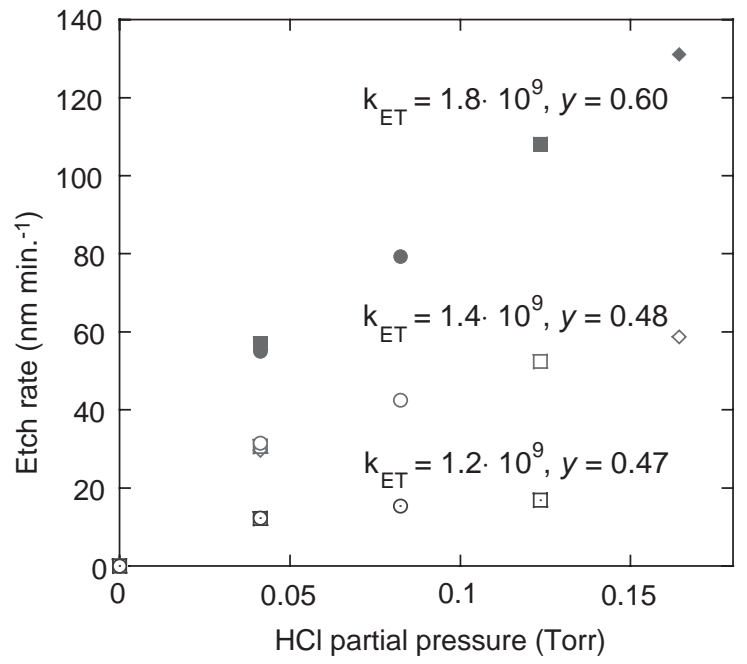

Fig. 7. Si growth rate at $750^{\circ} \mathrm{C}, 800^{\circ} \mathrm{C}$ and $850^{\circ} \mathrm{C}$ as a function of the hydrochloric acid partial pressure. The associated $k_{\mathrm{ER}}$ and $y$ values are given next to each curve. Lozenges, squares and circles correspond to $F\left(\mathrm{SiH}_{2} \mathrm{Cl}_{2}\right) / F\left(\mathrm{H}_{2}\right)$ mass flow ratios equal to $0.01,0.0075$ and 0.0050 , respectively. Full symbols (open symbols, open symbols with a dot in the middle) correspond to $850^{\circ} \mathrm{C}\left(800^{\circ} \mathrm{C}, 750^{\circ} \mathrm{C}\right)$ etch rates.

We have then plotted at $700^{\circ} \mathrm{C}, 750^{\circ} \mathrm{C}$ and $800^{\circ} \mathrm{C}$ the $\mathrm{Si}$ growth rate as a function of the $\mathrm{SiH}_{4}$ partial pressure in order to determine $k_{\mathrm{GR}}\left(\mathrm{SiH}_{4}\right)$ and $w$ (see Fig. 8). Mean values of $1.4 \times 10^{12}$ and $w=0.92$ are associated to those two constants. We thus have a close to linear $(w=0.92 \rightleftharpoons 1.0)$ dependency of the $\mathrm{Si}$ growth rate on the silane partial pressure (in agreement with previously reported results [35]), in stark contrast with the DCS, for which the dependency is strongly sublinear $(z=0.36)$. The fact that the growth rate is higher for silane that for dichlorosilane at a given temperature for the same mass flows [5] is partially accounted for by a rate constant more than twenty times higher for silane than for dichlorosilane $\left(k_{\mathrm{GR}}\right.$ $\left(\mathrm{SiH}_{4}\right)=1.4 \times 10^{12}$ versus $\left.k_{\mathrm{GR}}(\mathrm{DCS})=6.4 \times 10^{10}\right)$.

The $\mathrm{Si}$ growth rate (at 20 Torrs on blanket wafers) as a function of the $\mathrm{SiH}_{4}$ partial pressure (in Torr) and of the absolute temperature is thus given by:

$$
\begin{aligned}
& \mathrm{GR}(\mathrm{nm} / \mathrm{min}) \\
& \quad=1.4 \times 10^{12} \mathrm{e}^{-50.0 \mathrm{kcal} \mathrm{mol}^{-1} / k_{\mathrm{B}} T}\left(P_{\mathrm{SiH}_{4}}\right)^{0.92}\left(P_{\mathrm{H}_{2}}\right) .
\end{aligned}
$$

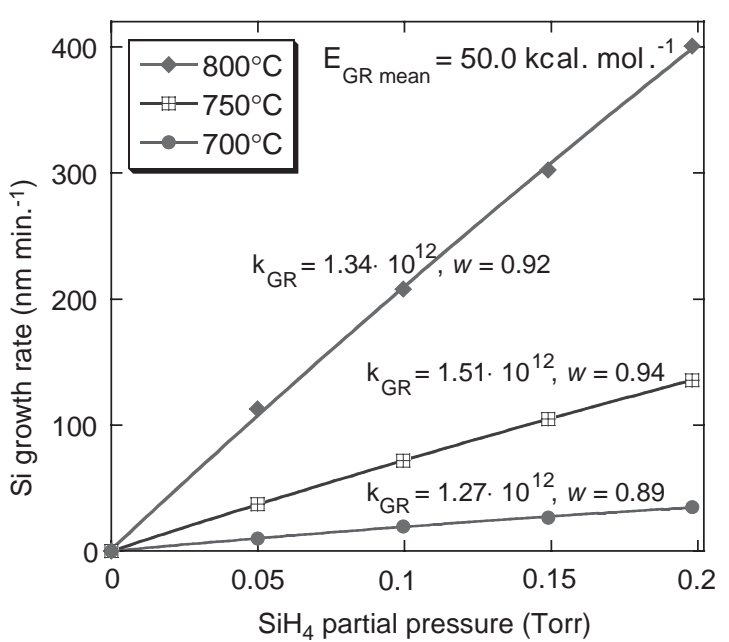

Fig. 8. Si growth rate at $750^{\circ} \mathrm{C}, 800^{\circ} \mathrm{C}$ and $850^{\circ} \mathrm{C}$ as a function of the silane partial pressure. The associated $k_{\mathrm{GR}}\left(\mathrm{SiH}_{4}\right)$ and $w$ values are given next to each curve.

This expression is valid in the low-temperature, $\mathrm{H}$-desorption limited regime (i.e. $T \leqslant 800^{\circ} \mathrm{C}$ ).

\section{Selective epitaxial growth of $\mathrm{Si}$ on patterned wafers}

We have also studied the low-temperature selective epitaxial growth of $\mathrm{Si}$ on patterned wafers using a dichlorosilane + hydrochloric acid chemistry. $92 \%$ of the surface area of those patterned wafers is covered by a $250 \mathrm{~nm}$-thick LOCOS (LOCal Oxydation of Silicon) type thermally grown $\mathrm{SiO}_{2}$ film. Si windows of varying sizes and shapes (mainly rectangular however, with sides along the $\langle 110\rangle$ directions) have been defined by optical lithography on each of the 49 dies $(18 \mathrm{~mm} \times 18 \mathrm{~mm}$ area each) of those patterned wafers. Those windows are approximately $110 \mathrm{~nm}$ below the surface of the LOCOS-covered parts of the wafers.

It is quite easy when plotting the Si deposited thickness as a function of the growth time to determine the associated growth rates (see Fig. 9). As far as the growth of Si using a dichlorosilane + hydrochloric acid chemistry is concerned, we have found on patterned wafers at $775^{\circ} \mathrm{C}$ 


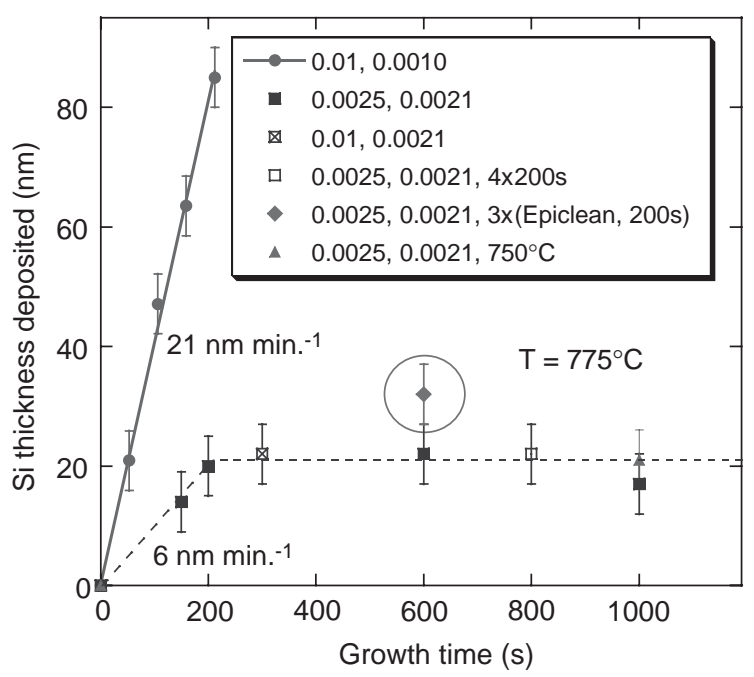

Fig. 9. Si thickness deposited inside $(110 \mu \mathrm{m} \times 110 \mu \mathrm{m}) \mathrm{Si}$ windows of patterned wafers using a dichlorosilane + hydrochloric acid chemistry as a function of the growth time. The $F\left(\mathrm{SiH}_{2} \mathrm{Cl}_{2}\right) / F\left(\mathrm{H}_{2}\right)$ and the $F(\mathrm{HCl}) / F\left(\mathrm{H}_{2}\right)$ mass flow ratios are (from left to right) the first and the second numbers next to each type of symbol in the figure insert, respectively. The Si layer of the $4 \times 200 \mathrm{~s}$ sample has been deposited in 4 times $200 \mathrm{~s}$, separated by growth interrupts under $\mathrm{H}_{2}$ for $50 \mathrm{~s}$. The $\mathrm{Si}$ layer of the $3 \times$ (EpiClean, $200 \mathrm{~s}$ ) sample has been deposited in three times $200 \mathrm{~s}$ of growth, separated by ex-situ wet "EpiClean" wet cleaning. The growth temperature was always $775^{\circ} \mathrm{C}$, except for one sample (for which it was $750^{\circ} \mathrm{C}$ ).

significant differences between high and low $F(\mathrm{HCl}) / F\left(\mathrm{SiH}_{2} \mathrm{Cl}_{2}\right)$ mass flow ratios (see Fig. 9).

For a $F(\mathrm{HCl}) / F\left(\mathrm{SiH}_{2} \mathrm{Cl}_{2}\right)$ mass flow ratio equal to 0.1 (i.e. $F\left(\mathrm{SiH}_{2} \mathrm{Cl}_{2}\right) / F\left(\mathrm{H}_{2}\right)=0.01$ and $F(\mathrm{HCl}) /$ $\left.F\left(\mathrm{H}_{2}\right)=0.001\right)$, the deposited thickness increases as expected linearly with the deposition time, with an associated growth rate of $21 \mathrm{~nm} \mathrm{~min}^{-1}$, very close to the one found on fullsheet wafers. Adding some $\mathrm{HCl}$ to $\mathrm{SiH}_{2} \mathrm{Cl}_{2}$ effectively suppresses at $775^{\circ} \mathrm{C}$ any global or local loading effect (i.e. the growth rate increase when switching between blanket and patterned wafers, and on patterned wafers between large and small $\mathrm{Si}$ windows).

With a $F(\mathrm{HCl}) / F\left(\mathrm{SiH}_{2} \mathrm{Cl}_{2}\right)$ mass flow ratio equal to 0.8 (i.e. $F\left(\mathrm{SiH}_{2} \mathrm{Cl}_{2}\right) / F\left(\mathrm{H}_{2}\right)=0.0025$ and $\left.F(\mathrm{HCl}) / F\left(\mathrm{H}_{2}\right)=0.0021\right)$, we are faced at $775^{\circ} \mathrm{C}$ (and $750^{\circ} \mathrm{C}$ ) with a limitation of the Si thickness deposited inside the $\mathrm{Si}$ windows of our patterned wafers at $20 \mathrm{~nm}$. What is quite puzzling however is that over the first $200 \mathrm{~s}$ of the growth, the Si growth rate is very close to that found on fullsheet wafers (i.e. $6 \mathrm{~nm} \mathrm{~min}^{-1}$ ). Keeping in mind that the balance between the pure growth rate by $\mathrm{SiH}_{2} \mathrm{Cl}_{2}$ and the etch rate by $\mathrm{HCl}$ might be affected by the fact that we are using patterned wafers, we have multiplied by four the $\mathrm{SiH}_{2} \mathrm{Cl}_{2}$ mass flow with the same $\mathrm{HCl}$ mass flow ( $\mathrm{Si}$ growth rate increase on fullsheet wafers from 6 up to $14 \mathrm{~nm} \mathrm{~min}^{-1}$ ), with no apparent effects. Growing for $800 \mathrm{~s}$ in 4 times $200 \mathrm{~s}$ separated by $50 \mathrm{~s}$ of growth interrupt under $\mathrm{H}_{2}$ (hypothesis that the etch rate becomes more important than the pure growth rate over time on patterned wafers) does not enable to exceed this $20 \mathrm{~nm}$ limit either. Thinking that this $20 \mathrm{~nm}$ limit might be due to some chemical poisoning of the surface, we have also tried after $200 \mathrm{~s}$ of growth to take the wafer out of the cluster tool, clean-up the surface with the "EpiClean" recipe, re-load it, bake it with $\mathrm{H}_{2}$ and deposit $\mathrm{Si}$ for another $200 \mathrm{~s}$, then do this sequence all over again. This way, we have obtained (instead of the nominal $3 \times 20 \mathrm{~nm}=60 \mathrm{~nm}$ ) a Si deposited thickness slightly above $30 \mathrm{~nm}$, which sort of validates at $775^{\circ} \mathrm{C}$ for high $F(\mathrm{HCl}) / F\left(\mathrm{SiH}_{2} \mathrm{Cl}_{2}\right)$ mass flow ratios this "chemical poisoning of the surface" theory. It should be noted that this $20 \mathrm{~nm}$ limit disappears (for the same $\mathrm{SiH}_{2} \mathrm{Cl}_{2}$ and $\mathrm{HCl}$ mass flows) at $800^{\circ} \mathrm{C}$ [18].

We have however to be sure that this $20 \mathrm{~nm}$ deposited thickness limit is not an experimental artifact linked to an unintended etch of the LOCOS during the growth and thus to a step height measurement which is meaningless. We have therefore exposed $22 \mathrm{~nm}$ thick $\mathrm{SiO}_{2}$ layers (grown at $800^{\circ} \mathrm{C}$ using a $\mathrm{SiH}_{4}+\mathrm{N}_{2} \mathrm{O}$ chemistry onto $\left.\mathrm{Si}\left(\begin{array}{lll}0 & 0 & 1\end{array}\right)\right)$ to either a $\mathrm{H}_{2}$ flow at $1100^{\circ} \mathrm{C}$ for up to $300 \mathrm{~s}$ or to a $\mathrm{HCl}+\mathrm{H}_{2}$ gaseous mixture $\left(F(\mathrm{HCl}) / F\left(\mathrm{H}_{2}\right)=0.0021\right)$ at $800^{\circ} \mathrm{C}$ for up to $1000 \mathrm{~s}$. The thickness difference as measured by $\mathrm{SE}$ is at most $0.25 \mathrm{~nm}$, meaning that almost no thermally stable $\mathrm{SiO}_{2}$ is consumed during a hightemperature $\mathrm{H}_{2}$ bake (prior to epitaxy) or a selective epitaxial growth using a $\mathrm{SiH}_{2} \mathrm{Cl}_{2}+\mathrm{HCl}$ chemistry. Similar conclusions were reached in the past by Oldham and Holmstrom [36] or Watts and Neudeck [37] (albeit at higher temperatures or higher growth pressures). 


\section{Si growth kinetics on SOI wafers}

Finally, we have worked on the growth of silicon (using either a) on SOIs substrates. Stateof-the-art SOI wafers from SOITEC with miscellaneous buried $\mathrm{SiO}_{2}(\mathrm{BOX})$ and $\mathrm{Si}$ over-layers' thickness were used for this study. The eventual thinning of the Si over-layer (from for example the typical $2000 \AA$ thickness of commercial wafers available nowadays down to $100 \AA$ ) was carried out thanks to several \{dry oxidation-wet deoxidation $\}$ cycles.

We have plotted in Fig. 10 the Si thickness deposited as a function of the growth time on bulk and on ultra-thin Si over-layer SOI substrates, this for a dichlorosilane only chemistry at $750^{\circ} \mathrm{C}$ or a dichlorosilane + hydrochloric acid chemistry at $800^{\circ} \mathrm{C}$. The $\mathrm{Si}$ growth rate (slope of the curves) is significantly lower on those ultra-thin SOI wafers than on bulk wafers for both chemistries. What is also quite obvious is that the $\mathrm{Si}$ growth rate decreases with the thickness deposited on those ultra-thin SOI substrates, as attested by the slope reduction with time.

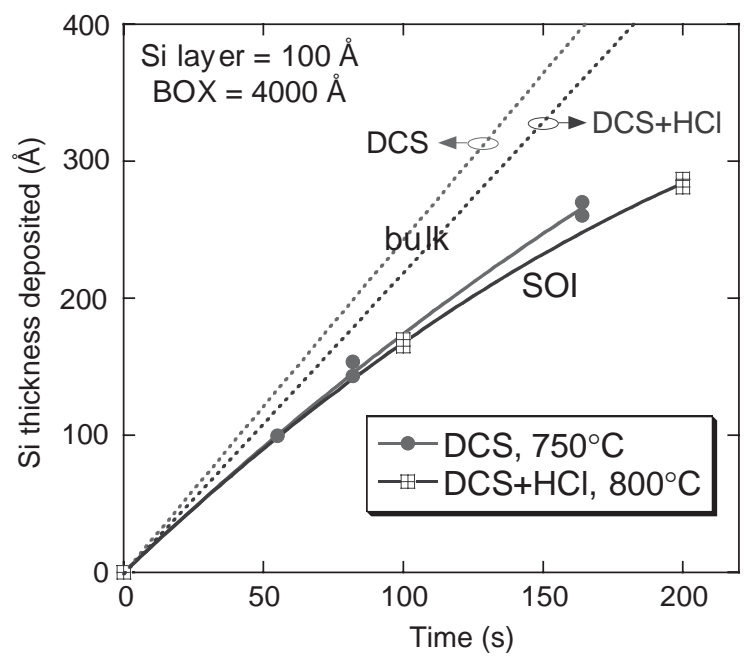

Fig. 10. Si thickness deposited as a function of the growth time on un-patterned bulk (dotted lines) and ultra-thin (Si: $100 \AA$, BOX: $4000 \AA$ ) SOI wafers (symbols linked by full lines). The $F\left(\mathrm{SiH}_{2} \mathrm{Cl}_{2}\right) / F\left(\mathrm{H}_{2}\right)$ and the $F(\mathrm{HCl}) / F\left(\mathrm{H}_{2}\right)$ mass flow ratios are equal to 0.0025 and 0.0021 , respectively. The growth temperatures are equal to $750^{\circ} \mathrm{C}$ and $800^{\circ} \mathrm{C}$ for the dichlorosilane only and the dichlorosilane + hydrochloric acid chemistries, respectively.
We have studied some of those ultra-thin SOI samples on which an epitaxy step was carried out using miscellaneous structural characterization methods. After the deposition of several tens of $\mathrm{nm}$ of $\mathrm{Si}$, the surface is smoother, as attested by the lower root mean square roughness than prior to epitaxy: $0.9 \AA$ versus $1.7 \AA$ (AFM, $(1 \mu \mathrm{m} \times 1 \mu \mathrm{m})$ fields). No $\mathrm{C}, \mathrm{O}$ or $\mathrm{F}$ contamination peak was observed in SIMS at the interface between the $\mathrm{Si}$ epilayer and the ultra-thin Si layer underneath for the kind of low thermal budget surface preparation described in Section $3\left(800^{\circ} \mathrm{C}, 2 \mathrm{~min} \mathrm{H}_{2}\right.$ bake). No interfacial contamination layer is observed in cross-sectional TEM either (see Fig. 11). The Si layer is perfect at the atomic scale, as attested by the absence of any defects such as stacking faults, etc. and by the prolongation of the atomic columns of the ultra-thin $\mathrm{Si}$ over-layer in the $\mathrm{Si}$ epilayer overhead.

A beneficial side effect of using an epitaxy step to thicken up the $\mathrm{Si}$ over-layer lays in the macroscopic smoothening of the surface. Indeed, the thickness standard deviation over a $200 \mathrm{~mm}$ substrate is typically of the order of $17 \%$ just after

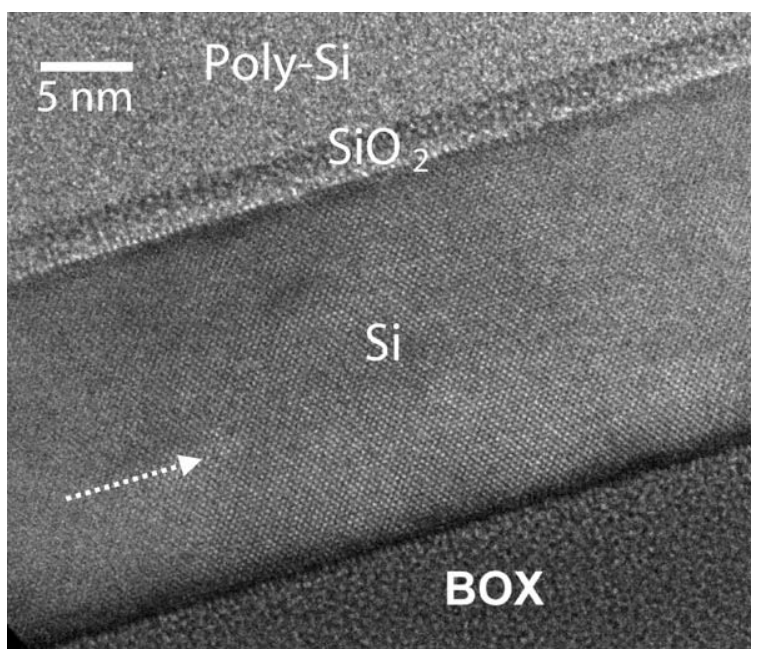

Fig. 11. Cross-sectional high-resolution transmission electron microscopy image of an ultra-thin SOI wafer on which an epitaxy step was carried out (sample subsequently capped by $3 \mathrm{~nm}$ of $\mathrm{SiO}_{2}$ and $75 \mathrm{~nm}$ of poly-Si). The dotted arrow shows the approximate boundary between the Si epilayer and the Si seed layer underneath. 


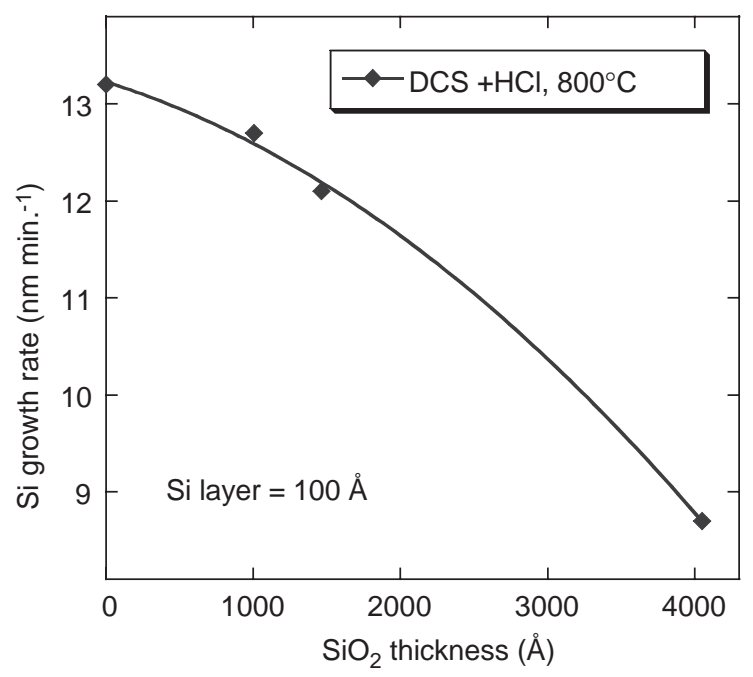

Fig. 12. Si mean growth rate (over $200 \mathrm{~s}$ of growth time) on ultra-thin (Si over-layer: $100 \AA$ ) SOI wafers as a function of the buried $\mathrm{SiO}_{2}$ thickness. The $F\left(\mathrm{SiH}_{2} \mathrm{Cl}_{2}\right) / F\left(\mathrm{H}_{2}\right)$ and the $F(\mathrm{HCl}) / F\left(\mathrm{H}_{2}\right)$ mass flow ratios are equal to 0.0025 and 0.0021 , respectively. The growth temperature is equal to $800^{\circ} \mathrm{C}$.

the several \{dry oxidation-wet de-oxidation thinning cycles necessary to bring the $\mathrm{Si}$ over-layer thickness from $2000 \AA$ down to $100 \AA$. After an epitaxy of $100 \AA$ of $\mathrm{Si}$, it drops down to only $3 \%$ (49 points wafer mapping in SE).

We have also studied the impact of the BOX thickness upon the growth rate of $\mathrm{Si}$ for the $\mathrm{SiH}_{2} \mathrm{Cl}_{2}+\mathrm{HCl}$ chemistry at $800^{\circ} \mathrm{C}$. Not unexpectedly, the $\mathrm{Si}$ growth rate converges towards the bulk value as the buried oxide gets thinner and thinner, as illustrated in Fig. 12. In the same manner, the growth rate, lower than the bulk value for ultra-thin SOI wafers (as illustrated in Fig. 10), increases with the Si over-layer thickness towards the bulk value. Indeed, the mean growth rate (over a 200 s growth time) on $100 \AA$ thick Si over-layers is equal to $8.7 \mathrm{~nm} \mathrm{~min}^{-1}$ for the $\mathrm{SiH}_{2} \mathrm{Cl}_{2}+\mathrm{HCl}$ chemistry at $800^{\circ} \mathrm{C}$ (buried oxide thickness: $4000 \AA$ ). It goes up to $12.3 \mathrm{~nm} \mathrm{~min}^{-1}$ for $1400 \AA$ thick $\mathrm{Si}$ over-layers. For bulk $\mathrm{Si}$, it is equal to $13.2 \mathrm{~nm} \mathrm{~min}^{-1}$.

To the best of our knowledge, only one other study has dealt with the growth kinetics of $\mathrm{Si}$ of SOI wafers [38]. On thicker SOI wafers (4000 BOX, $500 \AA$ thick Si over-layers), they have found that the growth rate, while being slightly lower than the bulk value for the first $1500 \AA$ of $\mathrm{Si}$ deposited (as in Fig. 10), increased more or less monotonously with the deposited thickness. For $4500 \AA$ of Si deposited, it was $25 \%$ higher than the bulk value. The behavior was explained in terms of wafer surface absorptivity and emissivity changes as the $\mathrm{Si}$ over-layer got thicker and thicker (see Ref. [38]).

\section{Conclusion}

Using a RP-CVD cluster tool, we have studied at a growth pressure of 20 Torr the growth kinetics of Si on fullsheet, patterned and SOI wafers using either a dichlorosilane + hydrochloric acid or a silane chemistry.

We have first of all developed a ("HF-last" advanced wet cleaning + an $800^{\circ} \mathrm{C}, 2 \mathrm{~min}$ in situ $\mathrm{H}_{2}$ bake) low-thermal budget combination that yields atomically smooth, $\mathrm{C}, \mathrm{O}$ and $\mathrm{F}$ free $\mathrm{Si}$ starting surfaces for both fullsheet and patterned wafers.

We have then modeled semi-empirically the Si growth rate with a dichlorosilane + hydrochloric acid chemistry on fullsheet wafers. It is given at 20 Torrs as a function of the $\mathrm{SiH}_{2} \mathrm{Cl}_{2}, \mathrm{H}_{2}$ and $\mathrm{HCl}$ partial pressures (in Torr) and of the absolute temperature $T$ by

$$
\begin{aligned}
\mathrm{GR}(\mathrm{nm} / \mathrm{min}) \\
=6.4 \times 10^{10} \mathrm{e}^{-49.3 \mathrm{kcal} \mathrm{mol}^{-1} / k_{\mathrm{B}} T}\left(P_{\mathrm{DCS}}\right)^{0.36}\left(P_{\mathrm{H}_{2}}\right) \\
-1.4 \times 10^{9} \mathrm{e}^{-34.3 \mathrm{kcal} \mathrm{mol}^{-1} / k_{\mathrm{B}} T}\left(P_{\mathrm{HCl}}\right)^{0.52} .
\end{aligned}
$$

This expression is valid in the low-temperature, $\mathrm{H}$-desorption limited regime (i.e. $T<1100 \mathrm{~K}$ ). Using silane instead of dichlorosilane as the $\mathrm{Si}$ gaseous precursor leads to the following dependency of the Si growth rate at 20 Torrs on the $\mathrm{SiH}_{4}$ partial pressure and the absolute growth temperature $T$ (valid for $T<950 \mathrm{~K}$ ):

$$
\begin{aligned}
& \mathrm{GR}(\mathrm{nm} / \mathrm{min}) \\
& \quad=1.4 \times 10^{12} \mathrm{e}^{-50.0 \mathrm{kcal} \mathrm{mol}^{-1} / k_{\mathrm{B}} T}\left(P_{\left.\mathrm{SiH}_{4}\right)^{0.92}\left(P_{\mathrm{H}_{2}}\right) .}\right.
\end{aligned}
$$

On patterned wafers, we are faced at $775^{\circ} \mathrm{C}$ (and $750^{\circ} \mathrm{C}$ ) with a limitation of the $\mathrm{Si}$ thickness deposited selectively inside the $\mathrm{Si}$ windows at 
$20 \mathrm{~nm}$ for high $F(\mathrm{HCl}) / F\left(\mathrm{SiH}_{2} \mathrm{Cl}_{2}\right)$ mass flow ratios. This limit (thought to be due to some sort of chemical poisoning of the surface) disappears when (i) the growth temperature is increased up to $800^{\circ} \mathrm{C}$ (ii) the $F(\mathrm{HCl}) / F\left(\mathrm{SiH}_{2} \mathrm{Cl}_{2}\right)$ mass flow ratio is substantially decreased at $775^{\circ} \mathrm{C}$.

Finally, we have found that the growth rate is significantly lower on ultra-thin Si over-layer SOI wafers than on bulk ones. The difference between the two kinds of substrates gets less and less pronounced as the buried oxide layer gets thinner and/or the Si over-layer thickness increases. A Si over-layer thickened by an epitaxy step is of high crystalline quality, with a flatter surface and a higher thickness spatial homogeneity over the wafer surface than just after the thinning-down cycles.

\section{Acknowledgements}

G. Rabillé is gratefully acknowledged for his help in operating the Epi Centura and for the studies of the possible etching effects of $\mathrm{SiO}_{2}$ by $\mathrm{H}_{2}$ or $\mathrm{HCl}$ studies. The authors would also like to thank Dr. V. Loup for fruitful discussions. This work was carried out inside the Silicon Technology Department of LETI, CEA-Grenoble.

\section{References}

[1] R. Hull, J.C. Bean, Germanium Silicon: physics and materials, in: R.K. Willadson, E.R. Weber (Eds.), Semiconductors and Semimetals, Vol. 56, Academic Press, SanDiego, 1999.

[2] F. Schäffler, Semicond. Sci. Technol. 12 (1997) 1515.

[3] T.E. Whall, E.H.C. Parker, Thin Solid Films 368 (2000) 297.

[4] L. Colace, G. Masini, G. Assanto, IEEE J. Quantum Electron. 35 (1999) 1843.

[5] J.M. Hartmann, V. Loup, G. Rolland, P. Holliger, F. Laugier, C. Vannuffel, M.N. Séméria, J. Crystal Growth 236 (2002) 10.

[6] J.M. Hartmann, F. Champay, V. Loup, G. Rolland, M.N. Séméria, J. Crystal Growth 241 (2002) 93.

[7] J.L. Regolini, D. Bensahel, J. Mercier, Mater. Sci. Eng. B 4 (1989) 407.

[8] M.R. Goulding, Mater. Sci. Eng. B 17 (1993) 47.

[9] J.T. Fitch, J. Electrochem. Soc. 141 (1994) 1046.

[10] L. Vescan, Mater. Sci. Eng. B 28 (1994) 1.
[11] I.J. Raajmakers, H. Sprey, A. Storm, T. Bergman, J. Italiano, D. Meyer, J. Vac. Sci. Technol. B 17 (1999) 2311.

[12] K. Miyano, I. Mizushima, K. Ohuchi, A. Hokazano, Y. Tsunashima, Jpn. J. Appl. Phys. 38 (1999) 2419.

[13] L. Huang, J.O. Chu, D.F. Canaperi, C.P. D'Emic, R.M. Anderson, S.J. Koester, H.S. Philip Wong, Appl. Phys. Lett. 78 (2002) 1267;

L. Huang, J.O. Chu, S.A. Goma, C.P. D'Emic, S.J. Koester, D.F. Canaperi, P.M. Mooney, S.A. Cordes, J.L. Speidell, R.M. Anderson, H.S. Philip Wong, IEEE Trans. Electron. Dev. 49 (2002) 1566.

[14] T. Mizuno, N. Sugiyama, T. Tezuka, S. Takagi, Appl. Phys. Lett. 80 (2002) 601;

T. Tezuka, N. Sugiyama, S. Takagi, T. Kawakubo, Appl. Phys. Lett. 80 (2002) 3560.

[15] N. Sugii, S. Yamaguchi, K. Washio, J. Vac. Sci. Technol. B 20 (2002) 1891.

[16] J. Pejnfors, S.-L. Zhang, J.V. Grahn, M. Östling, T.Winzell, in: M.D. Allendorf, M.L. Hitchman (Eds.), Chemical Vapor Deposition PV 2000-13, Vol. XV. The Electrochemical Society Proceedings Series, Pennington, NJ, 1999, p. 403.

[17] P. Holliger, F. Laugier, J.C. Dupuy, Surf. Interface Anal. 34 (2002) 472.

[18] J.M. Hartmann, A. Abbadie, F. Bertin, G. Rolland, F. Laugier, M.N. Séméria, P. Besson, P. Gentile, J. Crystal Growth, submitted for publication.

[19] P. Besson, C. Cowache, J.M. Fabri, F. Tardif, A. Beverina, Diffusion Defect Data Part B 76-77 (2001) 199;

P. Besson, C. Cowache, J.M. Fabri, F. Tardif, A. Beverina, in: Proceedings of the Fifth International Symposium on Ultra-Clean Processing of Silicon Surfaces (UCPSS'00), Ostend, Belgium, 2000, p. 199.

[20] B.S. Meyerson, F.J. Himpsel, K.J. Uram, Appl. Phys. Lett. 57 (1990) 1034.

[21] T.Y. Hsieh, K.H. Jing, D.L. Kwon, T.H. Koshmieder, J.C. Thomspon, J. Electrochem. Soc. 139 (1992) 1971.

[22] K. Oda, Y. Kiyota, J. Electrochem. Soc. 143 (1996) 2361.

[23] C.L. Wang, S. Unnikrishnan, B.Y. Kim, D.L. Kwong, A.F. Tasch, Appl. Phys. Lett. 68 (1996) 108.

[24] C.L. Wang, S. Unnikrishnan, B.Y. Kim, D.L. Kwong, A.F. Tasch, J. Electrochem. Soc. 143 (1996) 2387.

[25] M. Caymax, S. Decoutere, E. Röhr, W. Vandervorst, M. Heyns, H. Sprey, A. Storm, J.-W. Maes, Solid State Phenom. 65-66 (1999) 237.

[26] M.S. Carroll, J.C. Sturm, M. Yang, J. Electrochem. Soc. 147 (2000) 4652.

[27] O. Vatel, S. Verhaverbeke, H. Bender, M. Caymax, F. Chollet, B. Vermeire, P. Mertens, E. André, M.M. Heyns, Jpn. J. Appl. Phys. Part2 (32) (1993) L1489.

[28] H. Bender, S. Verhaverbeke, M. Caymax, O. Vatel, M.M. Heyns, J. Appl. Phys. 75 (1994) 1207.

[29] M.C. Hersam, N.P. Guisinger, J.W. Lyding, D.S. Thompson, J.S. Moore, Appl. Phys. Lett. 78 (2001) 886.

[30] P. Brabant, J. Wen, J. Italiano, T. Landin, N. Cody, L. Haen, in: Poster Presentation during the ISTDM 2003 Conference, Nagoya, Japan, 15-17th January 2003. 
[31] Y.W. Mo, M.G. Lagally, Surf. Sci. 248 (1991) 313.

[32] B. Voigtländer, T. Weber, P. Šmilauer, D.E. Wolf, Phys. Rev. Lett. 78 (1997) 2164;

B. Voigtländer, Surf. Sci. Rep. 43 (2001) 127.

[33] P. Kongetira, G. Neudeck, C.G. Takoudis, J. Vac. Sci. Technol. B 15 (1997) 1902.

[34] K. Sinniah, M.G. Sherman, L.B. Lewis, W.H. Weinberg, J.T. Yates Jr., K.C. Janda, Phys. Rev. Lett. 62 (1989) 567.
[35] W.A.P. Claassen, J. Bloem, J. Crystal Growth 51 (1981) 443.

[36] W.G. Oldham, R. Holmstrom, J. Electrochem. Soc. 114 (1967) 4.

[37] J.S. Watts, G.W. Neudeck, J. Vac. Sci. Technol. B 14 (1996) 1670.

[38] J. Pejnefors, S.-L. Zhang, H.H. Radamsson, M. Östling, Electrochem. Solid State Lett. 4 (2001) G98. 